\title{
"Being together in the locker room is great, but showering together - just forget it!" The Janus Face of the Wardrobe Practice in Physical Education
}

\author{
Bjørn Tore Johansen, PhD, Martine Mæhle, MSc, Øyvind Oland, MSc, \\ and Tommy Haugen, PhD \\ University of Agder \\ Kristiansand, Norway
}

\begin{abstract}
The aim of this study is to examine the wardrobe context among students in physical education (PE) in lower secondary school and describe their various experiences of the atmosphere in the locker room and their showering habits. 16 semi structured in-depth interviews with eight boys and eight girls, all aged 15, in the 10th grade (third and final year of lower secondary school) were conducted to grasp some of the ongoing interactions between students and the context of the wardrobe practice before and after PE lessons. The planning of the interviews is grounded in a variety of topics such as the class environment, the influence of teacher behavior, selfevaluation, and the role of social media. Four main categories emerged when describing the students' various experiences of the wardrobe practice in PE; 1) Friendship, 2) Physical Facilities, 3) Digital Life and 4) Shyness. Overall, the students feel comfortable as well as motivated for participation in the PE lessons and the atmosphere in the wardrobe seems to play a vital part. However, students may be exposed to an unhealthy body image through their fellow students, the role of social media, and the society's view of what is an ideal body. The results may suggest that in general puberty and the major bodily changes occurring in this age create unpleasantness and shyness of being exposed to other students previously unknown to them. Habitually, most of the girls choose not to shower while exposed to fellow female students after ended PE session while the boys who are showering do it in their underwear.
\end{abstract}

Keywords: Wardrobe practice; comradeship; puberty; shyness; showering habits 


\section{Introduction}

There are reasons to believe that students perceive the context of the wardrobe practice differently, and O'Donovan, Sandfjord, and Kirk (2015) argue that the wardrobe in physical education (PE) is perceived as a value-laden place where physical closeness to others can facilitate a process of comparison, monitoring, and self-regulation which may lead students to develop barriers for undressing and showering. Moreover, the mandatory practice of showering after PE lessons is long gone, and today the teacher, at least in Norway, has no further opportunity to decide whether the students should shower or not after PE lessons. Routine showering at school after PE seems to be relatively rare and may be causally related to lower physical activity levels and cardiorespiratory fitness, especially among girls (Sandercock, Ogunleye, \& Voss, 2014). In a study of English students Sandercock et al. (2014) documented that $53 \%$ of the total 2,141 boys and $67.5 \%$ of the total 1,779 girls choose to never be showering after PE lessons. In Norway, an informal online poll conducted by www.ung.no in March 2016, with 10,500 people responding revealed that seven students out of ten choose not showering after PE lessons (Ung.no, 2016). The question addressed on the website was: "Take a shower after PE classes?" and the results are indicating that a combination of several reasons play a part in explaining this perceived barrier for showering (frequency of answers in percent):

$34.5 \%$; Yes, it is important to shower after training

26.5\%; No, do not like being naked with other

17.5\%; Showers, but feel uncomfortable

7.1\%; $\quad$ Only if I get a private cubicle / cloakroom

5.9\%; $\quad$ Showers, but uses bikini / bathing shorts

$4.4 \%$; No, afraid someone will come in to see or take a picture of me

$4.0 \%$; No, the showers at school are dirty / nasty

Based on the results of the poll it is more than fair to claim that students in Norway feel a kind of embarrassment related to exposing their own body to others, even peers in their own class. May this perceived barrier be related to body image, nakedness itself, or is it general human shyness? Moreover, if students are reluctant to shower after physical education classes and reduce their own involvement in PE, the potential benefits of PE may not be realized (Sandercock et al., 2014). Consequently, for teachers in PE to fulfill the ambitious goal for the subject; "Physical education is a general education and a subject to inspire a physically active lifestyle and create lifelong enjoyment of movement" (Udir, 2016, p. 1), they seem to have a mountain to climb to create a positive learning climate.

However, as much as the shower habits among students is only a part of the wardrobe practice, there is also a need to clarify distinctions of the shower pattern. For instance, Sandercock et al. (2014) found that students who reported being physically active with their parents were $73 \%$ more likely to take a shower at school. This may reflect familial social norms and values around sport and exercise within families (Wheeler, 2012). Moreover, those who play team sports or those who work hard in PE tended to shower after PE lessons (Sandercock et al., 2014). Thus, the more positive shower pattern among active and team sport 
students documented by Sandercock et al. (2014) may be due to that the wardrobe or locker room in the sports context is where the club feeling is created, camaraderie developed, news can spread, and common values can be created. One may argue that the wardrobe at school is not exactly a place where "sport club feeling" is important, but can it function as an arena for forming companionship and belonging? Hence, Sandercock and colleagues (2014) claim there is little research examining the shower behavior in the school, and they suggest that the potential socializing effect of the wardrobe practice should be examined. Moreover, all human development and learning takes place in context (Bronfenbrenner, 1979), and our behavior is always shaped by the constraints of where we live and who we are (Silbereisen, 2003). Therefore, the primary subject of this paper is the repeated processes of increasingly complex interactions between an active receptor (e.g., student in PE) and the other individuals, objects, and symbols in the immediate surroundings (e.g., the wardrobe in PE). To grasp some of the meaning of the interactions going on in the wardrobe practice in PE, the shape, strength, content, and direction of these processes that vary systematically as a function of the overall characteristics of the person, as well as the physical and social environment (Bronfenbrenner, 1979; Bronfenbrenner \& Morris, 2006) should be examined. The individual is both a manufacturer of its own development and the result of development processes (Bronfenbrenner \& Morris, 2006). The acceptance of multidimensional relationships and interaction processes as a basis for development is essential in the quest for new knowledge (Magnusson, 2001). Even though the wardrobe context appears at school and during school time, it differs from the traditional school context in way that there is no teacher present and the students may feel free to play some music, be loud and extrovert with each other. Conversely, this context and its interactions may also for some students lead them to develop barriers for nakedness and showering ( $\mathrm{O}^{\prime}$ Donovan et al., 2015). Consequently, one may claim that the notion for investigating the development of the wardrobe practice in PE correspond to Bronfenbrenner's (1977, p. 513) view on research generally conducted on human behaviour:" ... the science of the strange behavior of children in strange situations..... ."' When human development occurs, it is in fact the interaction between human and human environment that has changed (Hutchins, 1995; Johansen, 2009; Lerner \& Damon, 2006). Moreover, Lerner and Damon (2006) clarifies that when we consider the context then it will first and foremost say that we recognize that we are all in constant interaction with complementary contexts of everyday life. Magnusson and Stattin (1998, p. 694) claim that to understand human development, behavior, and functioning, two parallel processes should be considered: "a) the continuously ongoing bidirectional process of interaction between the person and his or her environment, and b) the continuously ongoing process of reciprocal interaction among mental, biological, and behavioral factors within the individual". Høigaard and Johansen (2015) believe that the context in sport and PE refers to both a relationship and interaction, and the context change with different social contexts and environments. Thus, the social context may be different in the wardrobe in PE than for example in the class room. In PE lessons the students are often evaluated based on their demonstration of different skills and appropriate movements in sport activities, 
and not through oral or written sentences which most of the time is the case in the class room (Høigaard \& Johansen, 2015). There are reasons to believe that the students' self-evaluation, or at least part of it, in the PE lessons will influence their self-evaluation in the wardrobe practice before and after a PE lesson. This may be considered as a new context with different opportunities for different actions and realizations. However, it is still more or less a complementary context with the same individuals, and the behavior demonstrated in the wardrobe practice is most likely a result of the constraints in this "new" context perceived by the student based on for example the teacher behavior, peer relations, and self-perception in PE.

Consequently, the abovementioned contextualization and interactional assumptions of the wardrobe practice in PE provide consequences for methodological choice and/or instruments. Hence, the participants in this study will be interviewed and asked to elaborate on their thoughts and experiences related to their perception the wardrobe practice in PE including their showering habits. Therefore, the overall aim of this study is to investigate the students' experience of the wardrobe practice context prior to and after the PElessons.

\section{Method}

Participants

The participants in this study are 16 students (eight girls and eight boys, all aged 15 years) from 10th grade in a lower secondary school in southern part of Norway. In rural areas of Norway, students generally come from various school districts and different elementary schools before being assigned to new schools and classes at lower secondary level. To avoid factors such as insecurity of unfamiliar school environments, new class mates, and new teachers, students from the third and final year were recruited. Additionally, to gain variation of the students' experiences of the research topic at hand, different background among the selected participants was warranted. Therefore, two contact teachers were asked to select 16 students that voluntarily agreed to participate in this study after the following inclusion criteria; $10^{\text {th }}$ graders, age 15 years, different competencies in PE, different level of activity in PE lessons, and active in sports or not. The study has been approved by the Norwegian Social Science Data Services (NSD).

\section{Procedure}

All selected students expressed an interest in taking part and were orally informed about the study and their rights in accordance with ethical guidelines for social science. Written consent from the participants was obtained, in accordance with the National ethical regulations. The interviews were conducted at the students' school during the school day, located in convenient facilities. To create an optimal and adequate atmosphere, the semi-structured interviews were conducted by a female researcher for girls and a male researcher for the boys. The interviews lasted between 20 and 35 minutes and the audio-recordings were subsequently transcribed as textual files. The transcription-process resulted in a total of 128 pages of raw data (double spaced, font Times New Roman in Microsoft Office for Mac 2011, size 12). 
Instrumentation

Interview guide

A semi-structured interview guide was developed with the intention of exploring how a selection of informants experienced the wardrobe practice among students in physical education. The interview guide had questions relating to the informant's thoughts and experiences concerning perception of the teacher (e.g., Ommundsen \& Kvalø, 2007; Siedentop \& Tannehill, 1999), peer relations (e.g., Bjørnebekk, 2015; Siedentop \& Tannehill, 1999; Borgen \& Rugseth, 2014) self-evaluation (e.g., Cash \& Pruzinsky, 1990; Harter, 2000; Kvalem, 2007; Zimbardo, 1981) and digital environment (e.g., Bjørnebekk, 2015; Moen, Westlie, Brattli, Bjørke, \& Vaktskjold, 2015). Figure 1 illustrates the four main themes used to highlight the topic "wardrobe practice among students in physical education".

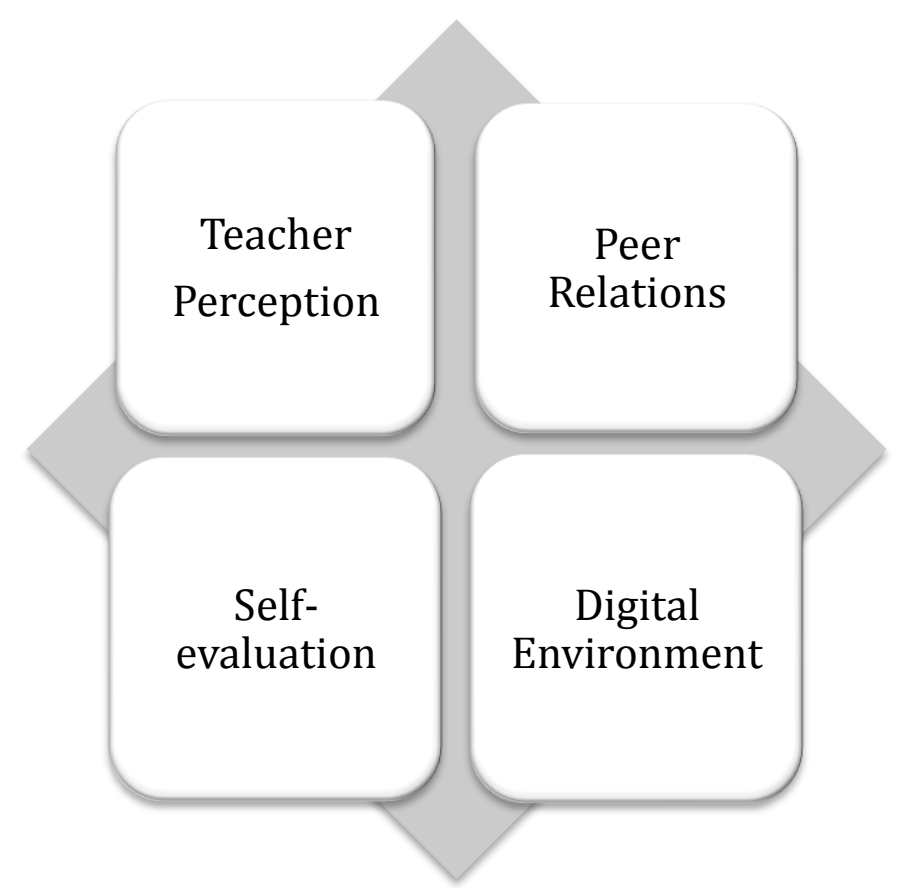

Figure 1: The figure shows the four main themes in the interview guide.

Note. The grey background area represents the contextual and interactional life of the wardrobe practice experienced by the students participating in this study (see Bronfenbrenner \& Morris, 2006).

\section{Data analysis}

The interviews verbatim were transcribed immediately after completion and subject to a descriptive phenomenological analysis (Robinson \& Englander, 2008). The four steps of Giorgi's (1985) human scientific method were used to explicate the data. Step one and two are mainly practical steps and required reading of all the raw data and sorting it into meaning units (Robinson \& Englander, 2008). Step three required transformation of the data to a physical education science perspective through describing the meaning of the text (Robinson \& Englander, 2008). In the last step Microsoft Excel was used to organize and sort data in emerging primary and secondary categories. This 
process was repeated to gain a better overview to ensure that the most exact meaning units and categories of descriptions were found (Malterud, 2012).

\section{Results}

The experiences of each student of the wardrobe practice in PE appeared to follow a similar pattern or sequence of events. After the data analysis four main categories of description emerged; 1) Friendship, 2) Physical Facilities, 3) Digital Life and 4) Shyness as illustrated in Figure 2. The result section will provide an overview over these categories, including sub-categories, accompanied illustrating quotations.

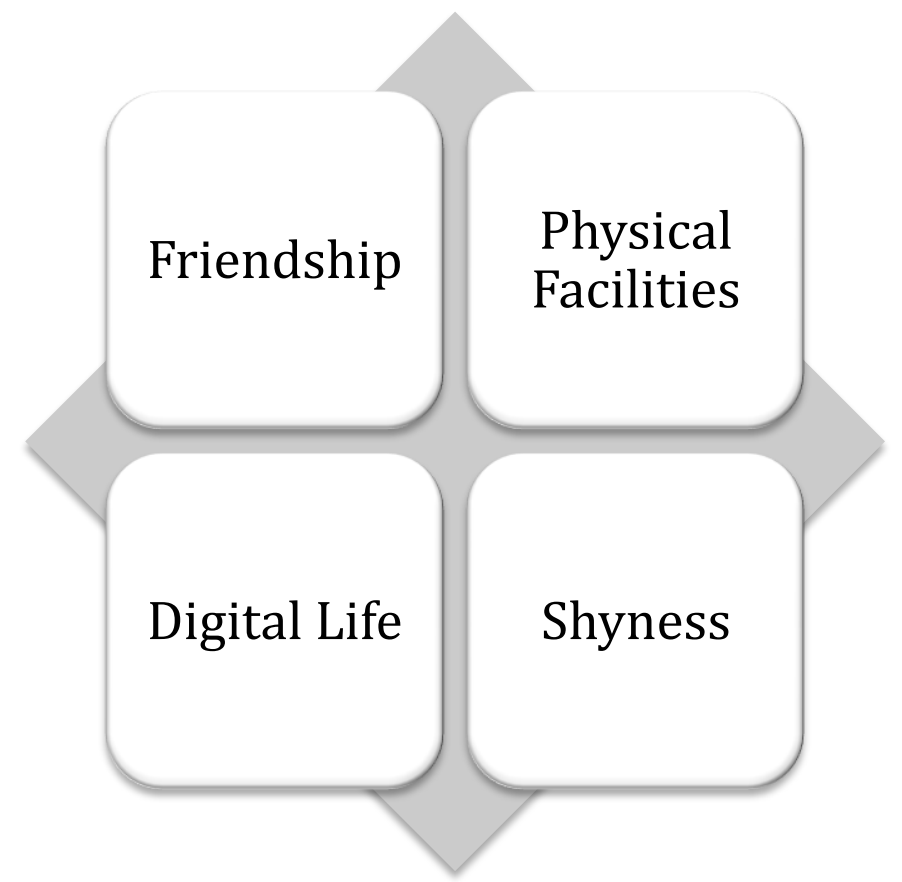

Figure 2: The figure shows the four main categories that influence the students' experience of the wardrobe practice in $\mathrm{PE}$, emerging from the data analysis.

1) Friendship

"Room of Cohesion"

The wardrobe in PE seems to be a room where students thrive. They say that it is socially, they sing, they dance, they talk, and they fool around;

"In the dressing room there is really very good atmosphere, lots of singing, chatting and dancing. (...) It's usually just that we are kidding and having fun. It's just that it's a fun place to be. One can be loud without it having any consequences, without anyone necessarily pays attention to you."

Several students are talking about that the wardrobe may be forming good cohesion between students. They are gathered together at the same place and this has a positive effect among them;

"No, it's nice there. We're good buddies and friends all together. We always have something to talk about. We thrive in wardrobe. (...) Indeed, it is a place we all have in common. When its break time in the school yard, everyone goes everywhere." 
"Togetherness and Enjoyment"

Overall the interviewees expressed a general perception that they enjoy school, in the wardrobe, and that they thrive well in PE lessons. The students claim that physical education is a subject they learn a lot and emphasize cooperation, respect, fun, variety, and motivation as the main factors for the well-being. One student reported;

"Everyone takes the initiative, and everyone has at least one friend. So, there is a sense of solidarity. It is good. We work and there is nothing negative. We respect each other for what we are, whether we participate in gym class or not."

The perspective of enjoyment is pinpointed by a participant as; "Perhaps, because many people find it fun. At least in the gym room, so they think it is very fun with different activities and stuff." The enjoyment through variation in PE is underlined by a participant as; "It's a lot of theory otherwise, so it's very nice with something practical."

\section{"Respect and Cooperation"}

The students experience the class in PE good at cooperating, provide excellent feedback, and they respect each other. Students believe that the teacher focuses on fair play, which has a positive impact on attitudes to each other. The learning environment in PE seems therefore to be supportive and they are good at encouraging each other also in the wardrobe;

"That's cooperation then. We are a very tight-knit class."; "Yes, they are good at making positive things and are encouraging."; "We are quite confident in each other."

Asked what the teacher focuses on in PE lessons concepts such as fair play, well-being, enjoyment and effort are reported;

"Hmm, you learn that it's smart to put in maximum effort and do the best you can in addition to fair play. That's what our teacher says something about. (...)

Partnership, positive comments, helpful feedback, and some different stuff. "

Students were asked what makes a teacher a good PE-teacher. Some students reported that they found that the teacher him/herself should participate in activities during lessons as they believe this might increase the motivation of students and their perception of the wardrobe practice;

"As long as there is a physical education teacher who is active. It is a plus if the gym teacher can participate in the activities themselves. I do not think it is any fun when gym teacher just sits on the bench. (...) She sits mostly on the bench and note if she sees something. It has been okay so far but I think it would be more fun if she had been running along with us."

"The positive feedback on how you are doing it. For example, in the gym then, they [the teachers] say your name and tell you what was good. Then you remember it longer and at least until the lesson is over."

\section{2) Physical Facilities}

A very characteristic observation in this study is the distinguishing difference students make between the locker room and the shower room in their experience of the wardrobe practice in PE. While the social environment connected to the wardrobe situation was experienced as positive, the physical 
environment or more precisely the built environment exemplified through shower facilities played a more multifaceted role.

"The lack of Shower Facilities"

The results revealed that bad shower facilities at the school influenced the students' experiences of the wardrobe practice and even their behaviour during the lesson in PE;

"Showers are old and ugly, there are cracks in the tiles and there is almost no water pressure in the showers."

"It's dirty and it tempts not exactly going in there [in the shower], and in that way, it affects how you are working in the gym, so one cannot do everything, because you cannot shower afterwards."

When students were asked about the showering habits and why it was more or less okay for students to undress in front of each other but not to take a shower together they emphasized the significance of better facilities and shower routines among the students;

"Best had probably been if all had showered. (...) And in the wardrobe, it should be a change that people should shower more."

"Inserting cubicles, shower curtains, and private locker rooms would have helped but the cubbyholes are not a guarantee that they choose to shower. But shower curtains most certainly."

"Lack of Privacy"

When the students were asked about the showering habits body pressure and body focus were mentioned as reasons for not taking a shower after a PE lesson;

"It may be some do not like that the showers are so close together. It's sort of half a meter to one meter between each shower. They may be afraid that others will see "the knob" maybe. (...) Most tend to have soap or boxer in front when they enter." "Although we have a very good class, people can be insecure about their body ... that there is a bit like that if they see that no one showers, then they think that, nor can I shower because then they will look down on me... "

"It's probably due to body pressure, and that they do not feel safe in class ... for ... it's showering together with someone. It's sort of very embarrassing ..."

"I do not think so much about it, but ... no, it is quite normal [not to shower]."

"I think I'm a little afraid of being judged or that other girls in the class will judge me because of my body."

The respondents were also asked about the practice in the locker room when someone was having a shower. A male student reported;

"We stand with "the knob" against the wall. It is silent. Or maybe someone ask if they can borrow soap or something. Maybe we are not so fond of showering with others. We like to keep things a little private, not too fond of showing off "the knob" to others."

"It's more thigh against thigh. There are those on our side who are close. It's sort of just a small half meter, and when one is naked it is found within the intimate zone really." 


\section{"Exposed to Puberty"}

Some of the students refer to puberty and the transition phase over to a new school and new classmates as plausible reason for discomfort. There are also students who demonstrate that puberty and new hair growth makes it uncomfortable to shower naked together;

"No, I' $m$ a little unsure. When we went from elementary school, then had a shower we, yes, but when you get into a new school and new pupils, so it becomes a little embarrassing. When one begins not to shower, and it has just become a habit that one does not. (...) It is well because one will not show off some might not have reached puberty etc. Some may think it is embarrassing not to have come so far. (...) There is no shower culture here. "

"Probably because many reach puberty, and then the hairy some places, and so yeah ... (...) Yes, it is embarrassing then. (...) Firstly, it was a whole new class with new people, and then it's not the first thing one does to walk naked in the shower with."

"Think maybe it has something to do that they are afraid to show off their bodies, that they are unsafe. They are afraid to get ugly feedback, or little positive feedback / comments. Maybe there are some who find it unnecessary to shower, but I think most that it is what they are afraid of what other people think. (...) That body changed differently. Perhaps some feel uncomfortable if their body changed later than others, that they somehow feel they are not accepted."

\section{3) Digital Life}

All informants in the present study reported that they use different social media such as Facebook, Snapchat, and/or Instagram and they cannot imagine a life without them. How this use affects their experience of the wardrobe practice is somehow complicated to apprehend.

\section{"A Perfect Body"}

Some of the girls in study admitted that the various online services affect their relationship to their body. They reported the media can be both strengthen and weaken upon their confidence;

"I see the kind of girls who are really nice, and they have the body, right? But then you can feel better that you look like other girls that has forms and shapes like your own body, right? You can in a way look at yourself in the picture. One can somehow see that it is actually fine, and I might be good enough if she is good enough."

"It affects it really pretty much. People [class mates/friends] put the pictures of the sort when they are out and exercise, shirtless, or with only a bra or something like that, for them to show that they are fit and like that and to show as much of their bodies. And then it is very like the feeling you are not good enough, the other is thinner than yourself, and it affects it [body image] really quite a lot."

\section{"Likes and be Liked"}

The informants reported that social media is used to catch up on what friends are doing and that you have get as many "likes" as possible to get recognition. And what is posted seems to affect the students' body image; 
"It's always a real treat with much likes, but it is not what really matters. There are certainly many who like image to duplicate images somehow, but it is not certain that they actually like it."

"Yes, I feel it. One will often have as many as possible likes his picture, if you post something. To get some recognition then."

A boy in this study says that you notice what the girls press "like" and what they comment in relation to the images on social media and in media. It may seem that this creates an illustration of what is good and how you ideally should look like;

"Or it's like someone who sees the image, for example, if a girl scrolls down on Instagram and look at an image of a nice man with a good six pack and she says, "that's fine". Then perhaps the boy who sees that is feeling that it is a plus to have a great six pack."

"It might be that, but I think it is most especially on snap chat and Instagram in that regard. People post pictures where they are somewhat scantily dressed. Then people are in that way being influenced to look a little thinner or to have more muscle."

\section{"The Silent Pressure"}

Additionally, it seems to exist agreement or understanding among the students about liking each other's pictures and some believe that someone adds more "friends" to get more "likes" on their images, but nobody is talking about it in public;

"It depends a little on how many friends you have on Facebook, etc. I know usually all I have on Facebook. There are a lot that just add many without really knowing them to get more likes."

"It could be that the focus of social media is how you should look like and like it has meant that they did not feel they meet the requirements for how one should look like. It is well simply that they certainly feel insecure about themselves, and perhaps in some schools it's said that one gets to hear it if you are not this or that."

"It is a kind of body pressure out there [on social media], but that it is not being said aloud. Some of us call it a silent or silently body pressure. I think this is a part of the reason that the shower culture has become so taboo."

4) Shyness

\section{"Cover up and Hide"}

Shyness in terms of discomfort, embarrassment, and shame seems to be a common term about how students experience both the wardrobe situation and the showering habits in school. Furthermore, some of the students expressed how the feeling of discomfort presents itself when to change clothing and/or be naked in front of each other. The need to hide with towel or other clothing when they change is regarded as quite necessary;

"No, they like, go down t-shirt sort of ... It is only with your pants ... many standing with jacket still on so that it covers ... Maybe they do it to not see the body, I do not know ...".

"I think it has something with the body to do .... I am afraid to be judged, or that other girls in the class will judge me because of the body ".

"I don't shower because I' $m$ afraid to show myself." 
"But if you shower with boxer, for example, I think like most others that it's stupid to be scared. But no one says anything. It's sort of allowed to be you really. (...) No, there are not so many. We are about 4 or 5 that shower maybe."

"Intimate Zone"

The students reported that they feel discomfort in that the showers are so close together. They feel they come within intimate zone to another. A few did take a shower, but it still depends on whether they are sweaty or not;

"Depends on what we do in physical education class. Some activities will be sweatier than others."

"Surely no one had showered, but we had perhaps thought that one had to smell sweaty the rest of the day. It's someone who washes their arms."

\section{"Reduce Effort or Forget"}

Several girls in the present study reported that they deliberately lessened intensity level in PE because they did not want to take a shower afterwards and to avoid smelling sweaty. One of the girls deliberately forgot gym clothes if there was a risk to get sweaty;

"Yes, sometimes I don't bring gym clothes because of that [being in the locker room and/or need for showering]."

"We tend never to look exhausted after a hard lesson but if we had so I think I only had washed my face in a bit of water in the sink and under the arms and stuff. Do not think I ever have taken a shower."

\section{Discussion}

The overall purpose of this study was to investigate the wardrobe practice in PE and to examine how this context influence the students' experiences and their attitude towards the subject PE, and whether they shower or not after the lessons. After analysing all the interviews, four main categories emerged when describing the students' various experiences of the wardrobe practice in PE; 1) Friendship, 2) Physical Facilities, 3) Digital Life and 4) Shyness. Even though we put the students' experience in four various categories of descriptions they are all interwoven and equally highlight the phenomenon studied.

Nevertheless, the first reason for operating and presenting four distinct categories describing the students' experiences of the wardrobe practice in PE is to emphasize that these categories are not merely description but also represent an interpretation. In this study what we mean by interpretation is the adoption of a non-given factor to help account for what is in the students' experience, such as a theoretical bearing, a hypothesis, or an assumption (Giorgi, 2012). In that way it is easier to reveal not only if students are showering or not after PE lesson (i.e., description) but what might be the reason behind their showering habits (i.e., interpretation). The second reason for the data presentation is that one may highlight the complexity of the phenomenon studied and grasp different distinctions and peculiarities of the informants' experiences (subcategories and illustrating quotations). Hence, the findings in this study have revealed that students in lower secondary school experience the wardrobe practice in PE both in a positive and in a negative way. Additionally, the contrast in the students' thoughts and feelings have painted a picture that vary 
from (1) that the wardrobe practice in PE is the greatest place and arena in school for growing friendship on one hand to (2) being a place and arena they almost hate and avoid being a part of if possible on the other hand. One may claim that for some of the students in the present study the wardrobe practice, and probably the PE subject itself, represent what we might call a Janus face, showing two different sides of one face. Moreover, the intricacy in the informants' different experiences in the present study also emphasize the value of using a contextual and interactional theoretical framework when describing and interpreting development and behavior among adolescents.

There is also a Janus face tendency when it comes to the showering habits of the students participating in this study, some did shower, and some did not. In line with previous research in the field (Bjørnebekk, 2015; Sandercock et al., 2014; O'Donovan et al., 2015; Moen et al., 2015) approximately $1 / 3$ of students did shower regularly after PE and there were more boys than girls showering. Almost everyone among the informants who did shower reported that they used underwear. Based on the participants' different background such as varying competencies for PE, diverse level of activity in PE lessons, and active in sports or not, provided by the contact teacher in advance, we found the same pattern of showering habits as in Sandercock et al. (2014). Students of high intensity level in PE lesson, occupied in sport, and girls participating in team sports were those who did shower after the lessons. Thus, findings related to shower habits in this study may reflect positive familial (parental) attitudes to physical activity in general or PE lessons at school (Birchwood, Roberts, \& Pollack, 2008; Wheeler, 2012). Interestingly, but not surprisingly, students who reported high selfconfidence and expressed a positive self-perception were also those who did shower. This well-being affects students at many levels will probably affect how students act socially and positive experiences of physical activity may create feelings of satisfaction and may be fun (Yli-Piipari, Watt, Jaakkola, Liukkonen, \& Nurmi, 2009). There are reasons to believe that these students don't perceive any barriers connected to nakedness nor exposing their bodies. However, most of the participants did report these barriers and felt quite some embarrassment connected to not only undressing and being naked in front of their class mates, but also standing close to another person when showering. This embarrassment is in line with what Zimbardo (1981) has described as a short-term acute loss of self-esteem and students seem to react with shyness. This situational embarrassment, like shame and shyness, seems to be triggered because of an unconscious and bodily mirroring process with others present, as Bjørnbekk (2015) also have demonstrated.

Additionally, other findings indicate that the shyness or the body image among the students may interact with the digital life they live. All informants reported that they were consumers of Facebook, Instagram, and/or Snapchat similarly to all their friends. They revealed that the use of social media when class mates or friends gave likes of posted picture of either a girl or a boy they know or any famous model, it influenced their perception of their own body. As pointed out earlier, the concept of body image is complex (Cash \& Pruzinsky, 1990; Harter, 2000; Kvalem, 2007; Tiggemann, 2014), and when the boys in this study were asked whether they are affected by the girls' views on the ideal body several answered without hesitating yes because they know what the girls in 
their class appreciate about the boys and their bodies, and what they comment on Facebook and Instagram. Nevertheless, the boys still seem to have a nuanced picture of the ideal body and reported that they are not so concerned if someone is thick or thin if they are satisfied themselves. Whether students' body image makes them unsafe in the locker room or the shower may be difficult to conclude, however, based on the present findings one may suggest that students' self-evaluation may vary with the different contexts they live in and are comfortable with. None of the informants reported that they were afraid of be filmed or taking a photo of in the wardrobe for this material to eventually being distributed. However, several participants pinpointed the backside of social media by reporting the huge pressure perceived should they not receive enough "likes" on their profile and, consequently, their popularity was sinking. This affected their well-being and their attitude towards school in general and the subject PE and the wardrobe practice in special.

In this study we have tried to shed some light on various aspects in and around the wardrobe practice in PE. The overall findings indicate that the wardrobe itself is perceived as positive. Students seem to thrive, they are enjoying chatting, singing, dancing, they fool around, and some students mentioned that there is even better well-being in the wardrobe than at recess. They are experiencing the wardrobe practice as unifying and social and this practice seems to lead to the formation of social relationships, particularly between the boys. However, when the informants were asked about the shower habits the situation abruptly contrasts. Most of students did not shower and according to several of the informants it seems like the transition between primary and secondary school is a critical period. Students come from different elementary schools and meeting with new students in a new class creates challenges in relation to shower together. Findings indicate that the body image and puberty have a vital role where the student feels uncomfortable with the rapid transformation of the body. This causes embarrassment, discomfort, and shyness even among $10^{\text {th }}$ graders knowing each other for more than two years. However, there seems to be a different trend when students talk about showering before and after swimming lessons. In this setting, it is regarded as normal behavior to shower and everyone does it some with swimming trunks/suits on while others with out. Students reported that it is easier to shower when everyone else is doing it and one would probably not be the one who will not shower.

Further, there seems to be several practical reasons for not showering. Reasons reported in this study are that it is better to shower at home if PE is the last lesson of the day, gym clothes occupies too much space in your pack, a lack of time, or that they are simply too lazy. Some students reported showering as too challenging work and there is simply no shower culture among these adolescents. In addition, some feel that they are not sweating enough during PE lesson and there is no point in showering. Whether the wardrobe practice has an influence for activity and participation in PE is difficult to conclude and is beyond the scope of this paper. However, based on most of the informants' experiences they thrive in the PE lessons and want to do their utmost to achieve the best possible grade. Based on this fact and that students want the PEteachers to be active themselves one may, perhaps, ask the question: Is the level 
of activity in PE lessons in this study at a level (so low) that the students find it not necessary to shower?

Strengths, limitations and implications

This study is not without its limitations and these issues should be considered when interpreting the findings. The limited numbers of participants in this study require carefulness in the interpretation process but the style of analysis employed was taken to establish validity and consistency of the data. In our opinion, the empirical material succeeds in saturating the phenomenon examined, meaning that it is sufficient to reveal the main aspects of students' experiences of the context wardrobe practice in PE and more interviews will probably not uncover something decisively new or different. Hence, Thelwell, Weston, and Greenlees (2005) pinpointed in their study of mental toughness in soccer that the interviews with six player generated data subject to the phenomenon examined that were more than adequate in terms of richness and content. Lincoln and Guba (1999) argue that a thick description and prolonged engagement are preconditions establishing trustworthiness of a qualitative study. Moreover, the strategic variation in the data generated from the 16 contributors in the present study should, therefore, be more than adequate to gain detailed descriptions of the phenomenon experienced by the informants (Malterud, 2012).

All quotations used in this article were translated from Norwegian to English. To avoid possible limitations in the analysis because of language the whole analysis process was completed in the original language (van Nes, Abma, Johnson \& Deeg, 2010). The findings in present study do not represent a diverse socio-economic group and a more heterogeneous population could provide insight into subcultural demands of students of different ethnicity and socioeconomic status. Common criticism of the phenomenological method is that different researchers may find dissimilar meanings in the same interview and because of this the method is not scientific (Kvale \& Brinkmann, 2009). Nonetheless, the researchers' background and pre-understanding can be an advantage in qualitative research because of the access gained into the informant's everyday world (Kvale \& Brinkmann, 2009). Robson (1993) argue that qualitative data often must face criticism that the work is unreliable and invalid and the problem, which is the central strength at the same time, is the reliance on the human instrument. Both these conditions are taken in consideration and strengthen trustworthiness in the present study.

In relation to the procedures that can be facilitated to get more students to thrive in the wardrobe and feel comfortable when showering after PE lessons, one may start with the physical facilities. Shower curtain/cubicles, private locker rooms, and at least modern and hygienic showering facilities are all a possible solution. However, given the complexity of the phenomenon studied there is no guarantee for minimization of the bodily embarrassment perceived by these adolescents. Moreover, this implies an economic burden most of the schools may be unable to bear. Further, the habit of not showering after a PE lesson appears to come from a kind of trend among the youth, and PE-teachers and parents should do a better job to motivate students for several reasons to take a shower. A better collaboration between school and home, especially 
regarding the transition from primary school to secondary school, seems to be warranted. A clarification of the role of the teacher in PE related to not only motivate but also gain more knowledge about what is going on in the wardrobe is recommended. However, adopting peephole in the teachers' wardrobe monitoring the students are not recommendable, but some closer mental attendances when students want to be seen either during the PE lesson or in the context of the wardrobe practice could be fruitful. These are just a few practical implications and assumptions that may help young people in a rapid and critical period of development and, hopefully, in the subject of PE to be inspired for a physically active lifestyle and create lifelong enjoyment of movement.

\section{References}

Birchwood, D., Roberts, K., \& Pollock, G. (2008). Explaining differences in sport participation rates among young adults: Evidence from the South Caucasus. European Physical Education Review, 14, 283-298. https://doi.org/10.1177/1356336x08095667

Bjørnebekk, W. (2015). Påkledd i dusjen: om ungdom og kroppspress. [Dressed in the shower: About adolescents and body pressure]. Oslo: Spartacus.

Borgen, J. S., \& Rugseth, G. (2014). Dusjing etter gymtimen har ingenting med helse å gjøre. [Showering after PE has nothing to do with health] Aftenposten, 26.09.14. Retrieved from https://www.aftenposten.no/meninger/debatt/i/vm1Xw/Dusjing-ettergymmen-har-ingenting-med-helse-a-gjore.

Bronfenbrenner, U. (1977). Toward an Experimental Ecology of Human Development. American Psychologist, 32(7); 513-531. https://doi.org/10.1037//0003066x.32.7.513

Bronfenbrenner, U. (1979). The Ecology of Human Development. Experiments by Nature and Design. Harvard University Press.

Bronfenbrenner, U. \& Morris, P.A. (2006). The Bioecological Model of Human Development (793-828). In R.M. Lerner, (Ed.), Handbook of child psychology sixth edition: Vol 1, Theoretical models of human development. NJ: John Wiley and Sons. https://doi.org/10.1002/9780470147658.chpsy0114

Cash, T. F., \& Pruzinsky, T. E. (1990). Body images: Development, deviance, and change. Guilford Press.

Giorgi, A. (Ed.). (1985). Phenomenology and psychological research. Duquesne University Press.

Giorgi, A. (2012). The descriptive phenomenological psychological method. Journal of Phenomenological psychology, 43(1), 3-12. https:// doi.org/10.1163/156916212x632934

Harter, S. (2000). Is self-esteem only skin-deep? The inextricable link between physical appearance and self-esteem. Reclaiming Children and Youth, 9, 133-138.

Hutchins, E. (1995). Cognition in the Wild. MIT press.

Høigaard, R. \& Johansen, B. T. (2015). Læring i idrettsgrupper - om utvikling, læring og prestasjoner i idrettsgrupper. [Learning in sport groups - development, learning, and performance in sport groups]. In H. Sigmundsson, \& J.E. Ingebrigtsen, (red.), Idrettspedagogikk [Sport Pedagogy] (2. utg.) (pp. 123-139). Oslo: Universitetsforlaget.

Johansen, B.T. (2009) Mesterlære i idrettspedagogikk - gammel vin i nye flasker? [Master-Apprenticeship in Sports Pedagogy - old wine in new bottles?] In B.T. Johansen, R. Høigaard, \& J.B. Fjeld, (eds.). Nyere perspektiv innen idrett og 
idrettspedagogikk. [New Perspectives in Sport and Sport Pedagogy] (pp. 79-91).

Kristiansand: Høyskoleforlaget.

Kvale, S., \& Brinkmann, S. (2009). Interviews: Learning the craft of qualitative research interviewing. Oslo: Gyldendal akademisk.

Kvalem, I. L. (2007). Ungdom og kroppsbilde. [Youth and body image] In L. Wichstrøm \& I. L.

Kvalem (Red.) Ung i Norge: psykososiale utfordringer [Young in Norway: psycho-social challenges] (pp. 33-50). Oslo: Cappelen akademisk forlag.

Lerner, R. M., \& Damon, W. E. (2006). Handbook of child psychology: Vol 1, Theoretical models of human development. NJ: John Wiley \& Sons Inc. https:// doi.org/10.1002/9780470147658.

Lincoln, Y. \& Guba, E. (1999). Establishing trustworthiness. In A. Bryman, \& R.G. Burgess (Eds.), Qualitative Research Volum III (pp. 397- 444) London: Sage Publications.

Malterud, K. (2012). Systematic text condensation: a strategy for qualitative analysis. Scandinavian Journal of Public Health, 40, 795-805. https://doi.org/10.1177/1403494812465030

Magnusson, D. (2001). The holistic-interactionistic paradigm: Some directions for empirical developmental research. European Psychologist, 6(3), 153 -162. https://doi.org/10.1027//1016-9040.6.3.153

Magnusson, D., \& Stattin, H. (1998). Person-context interaction theories. John Wiley \& Sons Inc.

Moen, K. M., Westlie, K., Brattli, V. H., Bjørke, L., \& Vaktskjold, A. (2015). Kroppsøving $i$ Elverumskolen. En kartleggingsstudie av elever, lærere og skolelederes opplevelse av kroppsøvingsfaget i grunnskolen. [Physical education in Elverum School. A survey study of pupils, teachers and school leaders' experience of physical exercise in primary school]. Oppdragsrapport nr. 2, Høgskolen i Hedmark.

O’Donovan, T., Sandfjord, R., \& Kirk, D. (2015). Bourdieu in the changing room. In L. Hunter, W. Smith \& E. Emerald (Red.), Pierre Bourdieu and Physical Culture. New York: Routledge.

Ommundsen, Y., \& Kvalø, S. E. (2007). Autonomy-Mastery, Supportive or Performance Focused? Different teacher behaviours and pupils' outcomes in physical education. Scandinavian Journal of Educational Research, 51, 385-413. https:// doi.org/10.1080/00313830701485551

Robson, C. (1993). Real world research. Oxford: Blackwell.

Robinson, P. \& Englander, M. (2008). Appliceringen av den deskriptiva fenomenologiska humanvetenskapliga metoden [Application of the descriptive phenomenological human scientific method]. Nordic Journal of Nursing Research, 28, 49-51. https:// doi.org/10.1177/010740830802800412

Sandercock, G. R. H., Ogunleye, A., \& Voss, C. (2014). Associations between showering behaviours following physical education, physical activity and fitness in English schoolchildren. European Journal of Sport Science, 16, 128-134. https://doi.org/10.1080/17461391.2014.987321

Siedentop, D., \& Tannehill, D. (1999). Developing Teaching Skills in Physical Education (4 $^{\text {th }}$ eds.): Mayfield Publishing Company.

Thelwell, R., Weston, N., \& Greenlees, I. (2005). Defining and understanding mental toughness within soccer. Journal of Applied Sport Psychology, 17, 326-332. https:// doi.org/10.1080/10413200500313636

Tiggemann, M. (2004). Body image across the adult life span: Stability and change. Body image, 1, 29-41. https://doi.org/10.1016/s1740-1445(03)00002-0

Ung.no. (2016). Dusjar du etter gymtimane? [Do you take a shower after PE lesson?]. Retrieved from https:/ / www.ung.no/vote/?idVote=258\&results=yes 
Utdanningsdirektoratet (2016). Læreplan i Kroppsøving [Curriculum in Physical Education]: KRO1-04 (LK06). Retrieved from http://www.udir.no/k106/KRO104/Hele/Formaal.

Wheeler, S. (2012). The significance of family culture for sports participation. International Review for the Sociology of Sport, 47, 235-252. https://doi.org/10.1177/1012690211403196

Van Nes, F., Abma, T., Jonsson, H., \& Deeg, D. (2010). Language differences in qualitative research: is meaning lost in translation? European journal of ageing, 7 , 313-316. https:// doi.org/10.1007/s10433-010-0168-y

Yli-Piipari, S., Watt, A., Jaakkola, T., Liukkonen, J., \& Nurmi, J.-E. (2009). Relationships between physical education students' motivational profiles, enjoyment, state anxiety, and self-reported physical activity. Journal of sports science $\mathcal{E}$ medicine, 8 , 327-336. PMCID: PMC3763276

Zimbardo, P. G. (1981). Shyness - what it is, what to do about it. Aschehoug - Oslo. 